\title{
Successful retrieval of an immovable pancreatic stent using a novel thin-tipped balloon catheter
}

Endoscopic pancreatic stenting for symptomatic strictures is beneficial to patients with chronic pancreatitis [1]. However, stent-related problems occur, including migration and immobility, which are more serious for pancreatic stents than for biliary stents because the pancreatic duct bends and is narrow [2]. We encountered a rare case with a pancreatic stent that could not be removed using forceps and was successfully retrieved using a novel thin-tipped balloon catheter.

A 77-year-old man with chronic pancreatitis was admitted for abdominal pain caused by a severe main pancreatic duct stricture. A 7-Fr plastic stent (Boston Scientific Corporation, Marlborough, Massachusetts, USA) was placed and his symptoms improved (• Fig.1). Endoscopic retrograde cholangiopancreatography (ERCP) was performed 3 months later to retrieve or exchange the stent. However, when we attempted to remove the stent with forceps, resistance was encountered, the stent did not move and part of it tore off ( $\mathbf{F i g . 2}$ ). This was probably associated with the severity and length of the stricture, and stent degradation. After the lumen of the stent had been cannulated with a 0.025-inch guidewire, a novel balloon catheter with a thinner tip (REN Biliary Balloon Dilation Catheter; 4-mm wide, 30-mm long; Kaneka Corporation, Osaka, Japan) was inserted, inflated inside the stent, and we attempted to pull the stent down ( Fig.3). The stent was successfully retrieved without any adverse events ( Video 1).

Although rare, an immovable pancreatic stent can be a major complication. Removal using forceps can tear off a plastic stent that is immobile and perishing. The novel balloon catheter used to retrieve the stent from this patient has a tapered and thinner 3-Fr tip that is of adequate

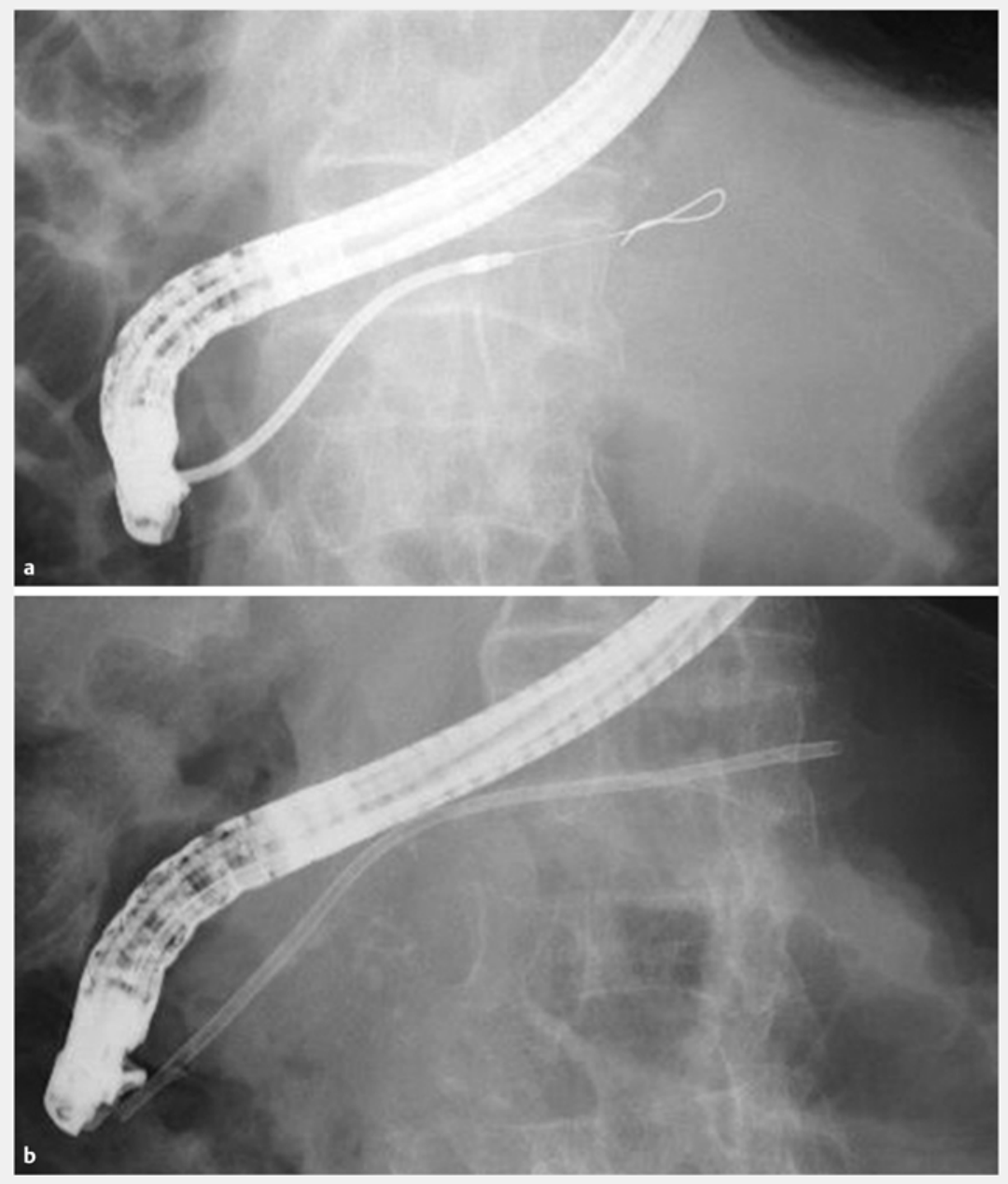

- Fig. 1 The main pancreatic duct stricture in the pancreatic body was 35-mm long and very severe. The procedure involved: a dilation using a Soehendra stent retriever (Cook Medical Inc., Bloomington, Indiana, USA); b placement of a 7-Fr plastic stent across the stricture.

rigidity (\$ Fig.4) [3]. Hence, when forceps cannot remove a pancreatic stent, balloon retrieval should be attempted, and the aforementioned thin-tipped balloon catheter may be more suitable for this procedure than other conventional balloon catheters.

Endoscopy_UCTN_Code_CPL_1AK_2AD

\section{Competing interests}

None 

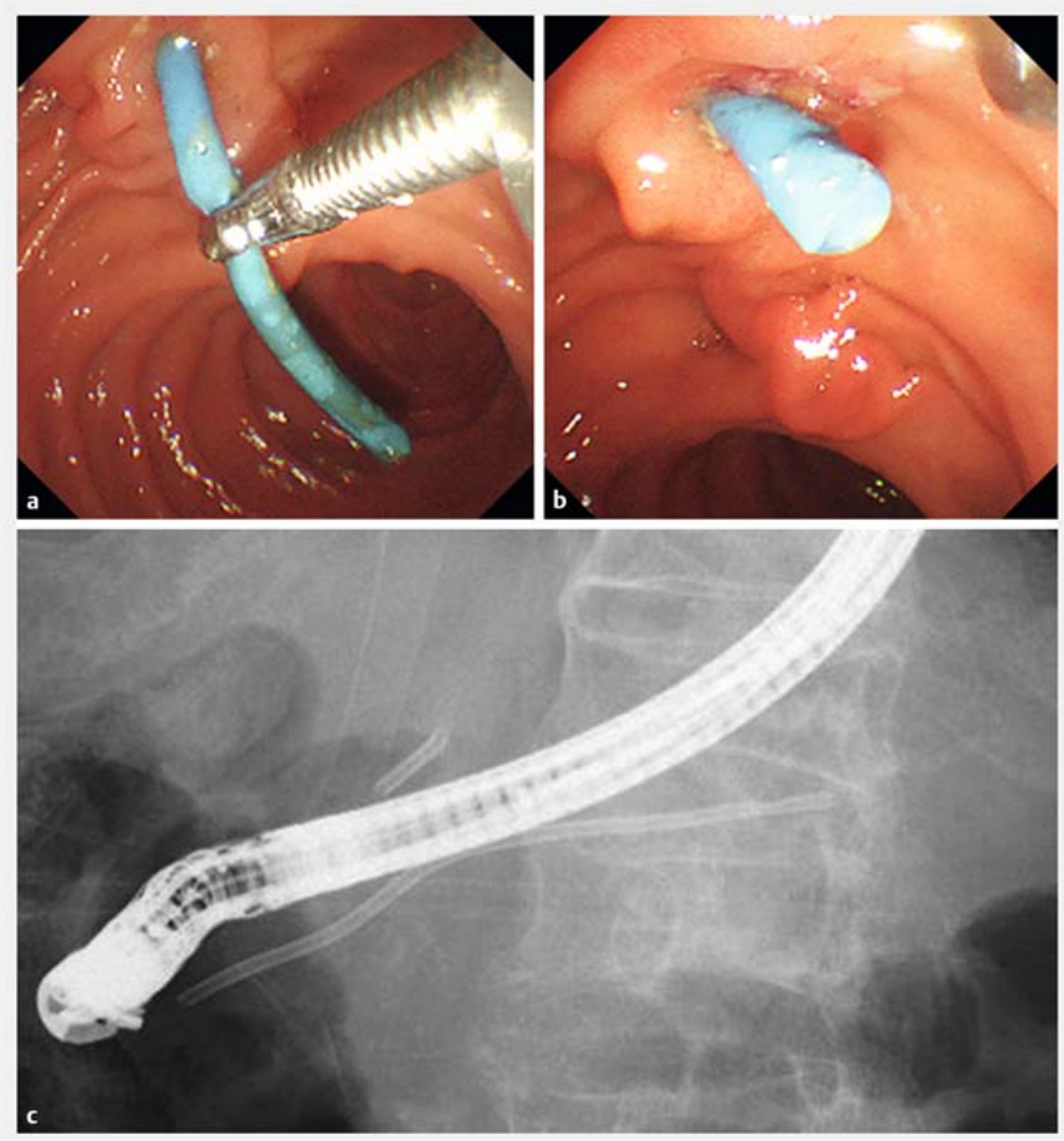

- Fig. 2 Images from an attempt to remove the pancreatic stent 3 months after its placement showing: $\mathbf{a}$ failure to remove the stent with forceps; $\mathbf{b}$ the remnant of the stent after part of it had torn off; $\mathbf{c}$ the torn-off section of stent present in the duodenal bulb.
The Authors

Tadahisa Inoue, Norimitsu Ishii, Yuji Kobayashi, Kiyoaki Ito, Masashi Yoneda

Department of Gastroenterology, Aichi Medical University School of Medicine, Nagakute, Japan

\section{Corresponding author}

\section{Tadahisa Inoue, MD}

Department of Gastroenterology, Aichi

Medical University School of Medicine, 1-1

Yazakokarimata, Nagakute, Aichi 480-1195, Japan

Fax: +81-561-633208

tinoue-tag@umin.ac.jp

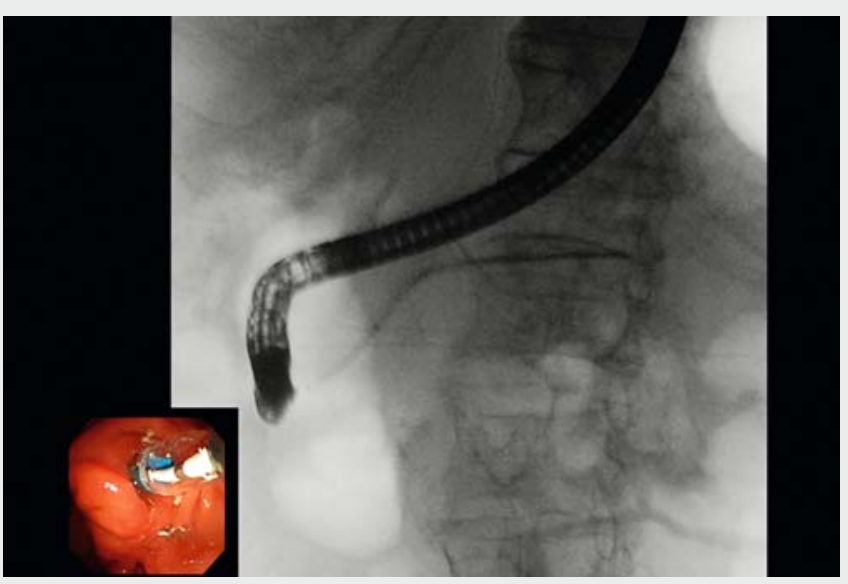

$\checkmark$ Video 1: The pancreatic stent could not be removed using forceps and part of it tore off. After a guidewire had been inserted, a balloon dilation catheter with a thinner tip was inserted and inflated inside the stent. The catheter was then pulled down, and the stent was successfully removed through the scope. 

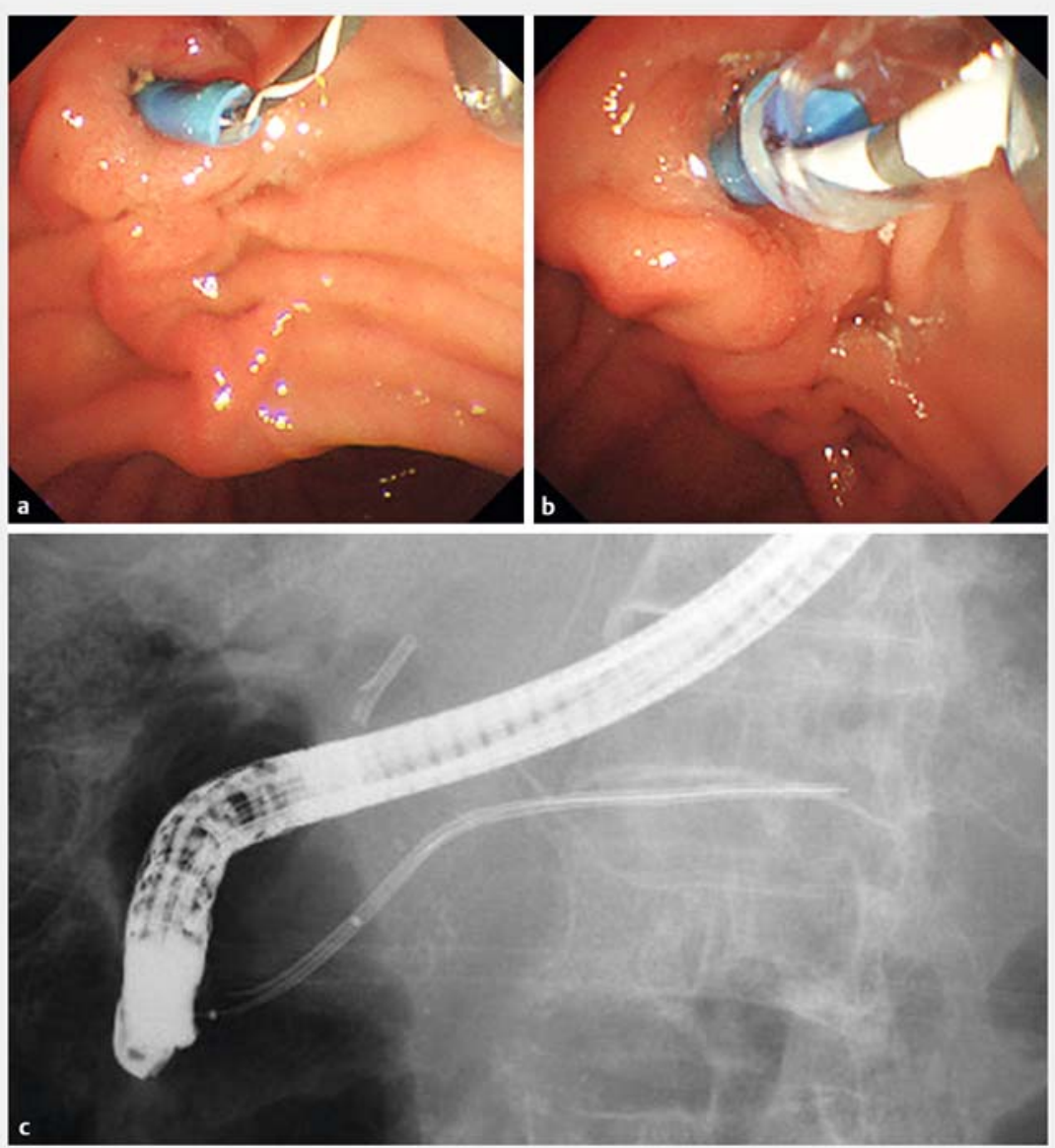

- Fig. 3 Images of the successful balloon-catheter removal of the stent showing: a a guidewire inserted into the stent's lumen; $\mathbf{b}, \mathbf{c}$ a balloon dilation catheter with a thinner tip inserted and inflated inside the stent, which allowed the stent to be pulled down.

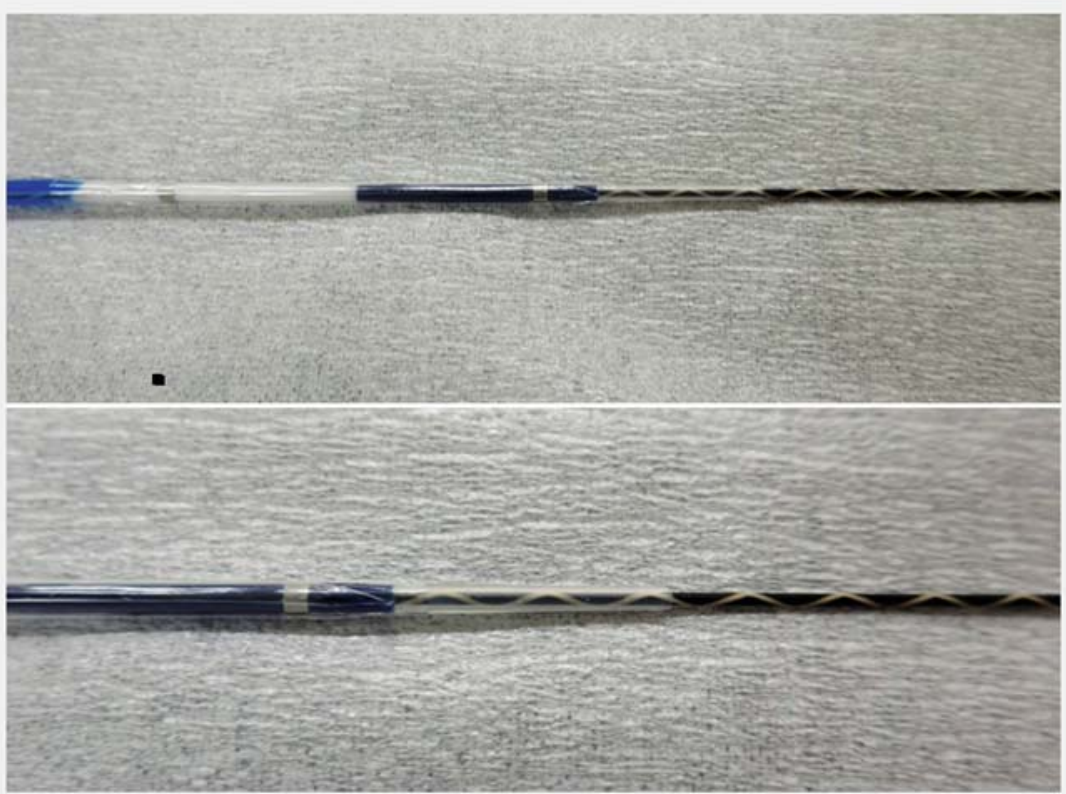

- Fig. 4 The novel balloon catheter has a tapered and thinner 3-Fr tip that has adequate rigidity and good pushability.

\section{References}

[1] Gabbrielli A, Pandolfi M, Mutignani M et al. Efficacy of main pancreatic-duct endoscopic drainage in patients with chronic pancreatitis, continuous pain, and dilated duct. Gastrointest Endosc 2005; 61: $576-581$

[2] Matsumoto K, Katanuma A, Maguchi H. Endoscopic removal technique of migrated pancreatic plastic stents. J Hepatobiliary Pancreat Sci 2014; 21: E34-E40

[3] Ogura T, Takagi W, Onda S et al. Endoscopic ultrasound-guided biliary drainage with a novel fine-gauge balloon catheter: simplified technique using a coaxial guidewire. Endoscopy 2015; 47 (Suppl. 01): E573E574

\section{Bibliography}

DOI https://doi.org/10.1055/s-0043-106734

Endoscopy 2017; 49: E157-E159

(c) Georg Thieme Verlag KG

Stuttgart · New York

ISSN 0013-726X

\section{ENDOSCOPY E-VIDEOS}

https://eref.thieme.de/e-videos

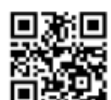

Endoscopy E-Videos is a free access online section, reporting 回的 on interesting cases and new

techniques in gastroenterological endoscopy. All papers include a high quality video and all contributions are freely accessible online.

This section has its own submission website at

https://mc.manuscriptcentral.com/e-videos 